\title{
Percepção das mães sobre a importância das práticas alimentares no tratamento da constipação crônica funcional
}

\author{
Mothers' perception about the importance of feeding habits in the treatment of functional chronic \\ constipation
}

Vivian Palo Pereira' ${ }^{1}$, Lilian Cristiane S. Medeiros², Patrícia da Graça L. Speridião ${ }^{3}$, Valéria Cristina A. Lisboa ${ }^{4}$, Soraia Tahan $^{5}$,

Mauro Batista de Morais ${ }^{6}$

\section{RESUMO}

Objetivo: Analisar o significado das práticas alimentares compreendendo as percepções, experiências e valores sobre a alimentação de mães de crianças e adolescentes com diagnóstico de constipação crônica funcional.

Métodos: 17 mães foram entrevistadas com base em um questionário semidirigido, que compreendia questões relacionadas à alimentação. Para análise, as falas foram agrupadas nos temas: "ambiente familiar durante as refeições", "dificuldades relacionadas à alimentação da criança e do adolescente", "atitudes das mães frente à recusa de alimentos" e "conhecimentos maternos sobre alimentação e sua relação com a constipação crônica funcional”.

Resultados: A idade das mães variou de 20 a 35 anos. A maioria era casada, possuía ensino fundamental incompleto e renda familiar entre dois e três salários mínimos. Observou-se, no relato das mães, que: muitas não consideram o momento das refeições em família agradável; a limitação financeira é a maior dificuldade relacionada à alimentação dos filhos; a maioria delas, frente à recusa alimentar, adota estratégias para convencer a criança a aceitar a refeição; demonstram ter noção da importância da alimentação para melhora da constipação; creem que alguns alimentos têm efeito "obstipante".
Conclusões: Mães de crianças com constipação intestinal crônica sabem que a alimentação é importante no tratamento dessa afecção e, no entanto, apenas uma parcela reconhece o papel das fibras alimentares. A refeição não é um momento prazeroso e o fator financeiro é limitante para definir os alimentos que compõem a dieta dessas crianças.

Palavras-chave: constipação intestinal; alimentação; criança.

\section{ABSTRACT}

Objective: Analyze the meaning of feeding habits according to the perceptions, experiences and values of mothers whose children and teenagers present functional chronic constipation.

Methods: 17 mothers were interviewed based on a semiconducted questionnaire about feeding habits. The answers were gathered as following: family environment during meals, difficulties related to the eating habits of the teenager/child, the mothers' attitude regarding food rejection and mothers' knowledge about feeding and its relation to functional chronic constipation.

Results: The age of the mothers varied from 20 to 30 years, they had not finished high school and had an income
Instituição: Disciplina de Gastroenterologia Pediátrica da Escola Paulista de Medicina da Universidade Federal de São Paulo (Unifesp-EPM), São Paulo, SP, Brasil

${ }^{1}$ Nutricionista, aluna de Mestrado do Curso de Pós-graduação em Nutrição da Unifesp-EPM, São Paulo, SP, Brasil

${ }^{2}$ Nutricionista, Doutora em Nutrição pela Unifesp-EPM, São Paulo, SP, Brasil

${ }^{3}$ Nutricionista, professora adjunta da Unifesp, Campus da Baixada Santista, Santos, SP, Brasil

${ }^{4}$ Psicóloga, Mestre em Pediatria e Ciências aplicadas em Pediatria pela Unifesp-EPM, São Paulo, SP, Brasil

${ }^{5}$ Médica assistente, Doutora da Disciplina de Gastroenterologia Pediátrica da Unifesp-EPM, São Paulo, SP, Brasil
${ }^{6}$ Professor-associado, livre-docente e chefe da Disciplina de Gastroenterologia Pediátrica da Unifesp-EPM, São Paulo, SP, Brasil

Endereço para correspondência:

Mauro Batista de Morais

Rua Pedro de Toledo, 441

CEP 04039-031 - São Paulo/SP

E-mail:mbmorais@osite.com.br

Recebido em: 30/5/08

Aprovado em: 11/9/08 
of two to three minimum wages. The following problems aroused from their answers: most of them did not consider sharing meals with their families a pleasant time; financial constrains are the biggest obstacle to feed their children; when their children refuse to eat, most of them adopt strategies to convince them to eat; mothers do have some knowledge about the importance of the intake of different kinds of food to improve their children condition; they believe that certain kinds of food contribute to constipation.

Conclusions: Despite knowing that the diet is important to the treatment of constipation, just a few mothers acknowledge the importance of dietary fiber. Meals are not a pleasant time for the families and financial problems limit the choice of proper food for these children.

Key-words: constipation; feeding; child.

\section{Introdução}

A constipação intestinal é um problema comum na infância e constitui a queixa principal em $3 \%$ das consultas pediátricas ${ }^{(1)}$ e em $25 \%$ das consultas de gastroenterologia pediátrica nos países desenvolvidos ${ }^{(2)}$. A maioria dos casos de constipação na infância (90 a 95\%) tem origem funcional ${ }^{(3,4)}$. Estudos brasileiros apontam uma prevalência elevada da constipação crônica funcional (CCF) na infância, variando de 14,7 a $36,5 \%(5,6)$.

O tratamento da constipação crônica funcional inclui orientação geral, esvaziamento do fecaloma, tratamento de manutenção e recondicionamento esfincteriano. Durante o tratamento de manutenção, recomenda-se uma dieta com alto conteúdo de fibras ${ }^{(7)}$, devido ao seu efeito sobre o trânsito intestinal ${ }^{(3)}$.

O comportamento alimentar infantil é determinado, em primeiro lugar, pela família da qual é dependente e, secundariamente, por outras interações psicossociais e culturais ${ }^{(8)}$. Os pais têm participação efetiva como educadores nutricionais ${ }^{(9)}$. Em especial, as estratégias que os pais utilizam, na hora das refeições, para ensinar as crianças o que e quanto comer desempenham papel predominante no desenvolvimento do seu comportamento alimentar ${ }^{(10)}$.

Um estudo ${ }^{(11)}$ analisou práticas alimentares de mães de crianças com diferenças culturais e econômicas e suas percepções sobre o peso corporal de seus filhos. Observou-se que o questionário semidirigido é um instrumento auxiliar rico em informações para futuras intervenções de profissionais nutricionistas na prática alimentar saudável para as famílias.
Este estudo tem com objetivo analisar a percepção das mães sobre a importância das práticas alimentares no tratamento da constipação crônica funcional de seus filhos.

\section{Métodos}

O estudo foi realizado no ambulatório de Motilidade Digestiva da Disciplina de Gastroenterologia Pediátrica da Universidade Federal de São Paulo (Unifesp). A amostra estudada foi de mães de crianças e adolescentes atendidos no ambulatório com diagnóstico de constipação crônica funcional.

Os critérios de inclusão adotados foram: diagnóstico de constipação crônica funcional, idade entre três e 15 anos e pacientes que não receberam orientações nutricionais no ambulatório. Como critérios de exclusão, destacam-se: constipação de origem orgânica, pacientes sem acompanhamento de suas respectivas mães no dia da consulta e recusa a participar do estudo.

Os dados sobre condições socioeconômicas, escolaridade, procedência e estado civil dessas mães foram coletados por questionário padronizado. Para avaliar os hábitos alimentares, realizou-se uma entrevista com a mãe por aproximadamente dez minutos. Essa entrevista era constituída por um questionário semidirigido, adaptada de um estudo de Sherry et $a l^{(11)}$. As questões foram:

1. Pense em um momento comum de alimentação, em que você esteja junto de seu filho.

a) Quem normalmente participa desse momento?

b) Qual é o humor nesse momento?

2. O que influência o tipo de alimento que você vai servir em casa? Por exemplo: dinheiro, transporte, disponibilidade para compra, etc.

3. Você acha que depois que seu(ua) filho(a) começou a apresentar sintomas de constipação você teve mais dificuldade para que ele(a) aceitasse a alimentação?

4. O que você faz quando seu filho se recusa a comer?

5. O que você gostaria que seu filho(a) comesse, mas que ele(a) não aceita?

6. Existe algum alimento que você não goste que seu filho(a) coma demais?

7. Existe algum alimento que você oferece a seu filho(a) para ajudá-lo(a) a se sentir melhor, para mantê-lo(a) quieto(a) ou, quando chateado(a), para fazê-lo(a) parar de chorar?

8. Na sua opinião, seu filho(a) se alimenta bem ou mal? Por quê?

9. Você evita oferecer algum tipo de alimento por achar que pode ajudar a "prender o intestino"? Qual(is)? 
10. Você acha que a alimentação tem importância no tratamento da constipação? Por quê?

A entrevista foi gravada em áudio para posterior transcrição e análise por profissionais de psicologia e nutrição. Optou-se por uma avaliação qualitativa do material coletado a fim de se observar os significados e representações que a alimentação tem para as mães de crianças com constipação crônica funcional.

$\mathrm{Na}$ categorização das entrevistas com as mães, as falas foram agrupadas em temas com base nos critérios adotados por Marins ${ }^{(12)}$, que avaliou a alimentação de pré-escolares segundo a percepção de suas mães. Os temas são os seguintes: ambiente familiar durante as refeições; dificuldades relacionadas à alimentação da criança e do adolescente; atitudes da mãe frente à recusa de alimentos e seus conhecimentos acerca da alimentação e sua relação com a constipação crônica funcional.

Após a coleta de dados, as mães entrevistadas e os pacientes passaram pela consulta com a nutricionista pesquisadora e receberam orientações quanto a uma dieta rica em fibras e líquidos para o auxílio no tratamento da constipação crônica funcional. O projeto foi aprovado pelo Comitê de Ética em Pesquisa da Unifesp-EPM.

\section{Resultados}

As características gerais das mães entrevistadas encontramse na Tabela 1. Com relação à idade, houve predomínio na faixa etária de 20 a 35 anos. A maioria das mães era casada, possuía $1^{\circ}$ grau de escolaridade incompleto e renda familiar entre dois e três salários mínimos.

$\mathrm{Na}$ Tabela 2 estão descritos os quatro principais temas relacionados às características, atitudes e práticas adotadas pelas mães quanto à alimentação de seus filhos.

Com relação ao primeiro tema, o ambiente familiar durante as refeições, observou-se que, na maioria dos casos, a criança tem a companhia da mãe e de outros familiares; entretanto, 47,1\% (8/17) das mães não consideram o momento das refeições agradável, como pode ser visto em algumas falas: "O bumor durante as refeições é ruim porque tem que ficar brigando para ela comer"; "Quando está todo mundo reunido, a bagunça é demais, tem muita falação".

No segundo tema relacionado às dificuldades na alimentação, a limitação financeira foi apontada por 83,2\% (14/17) das mães como o fator que mais influencia a aquisição de alimentos. Observa-se, também, essa situação nas falas das mães, quando questionadas se o filho se alimenta bem ou mal: "Depende porque nem sempre eu tenho dinheiro pra dar tudo o que ela pede. Às vezes, ela pede purê de batata e eu não tenho dinheiro para comprar"; "Mal porque não tem dinheiro toda semana para ir à feira comprar legumes e verduras"; "Mais ou menos. Ele échegado a fruta, mas não é toda vez que eu tenho dinheiro para comprar"; "Quando meu marido ficou desempregado, ele não comia bem, pois a gente recebia doação da igreja e, então, eu falava para ele comer o que tinha, o que eu podia dar".

Quanto ao terceiro tema, atitudes da mãe frente à recusa de alimentos, destacam-se as seguintes falas: "Antigamente, quando ele era menor, eu forçava ele a comer, mas hoje já não, às vezes o que ele come já é o suficiente para ele, não adianta forçar"; "Ah, normal, toda criança tem seu limite. Eu só fico preocupada se forem vários dias consecutivos, aí me preocupa, mas se for um dia

Tabela 1 - Características gerais da população estudada

\begin{tabular}{|c|c|c|}
\hline & Número & $\%$ \\
\hline \multicolumn{3}{|l|}{ Idade materna } \\
\hline 20-35 anos & 13 & 76,5 \\
\hline $36-55$ anos & 4 & 23,5 \\
\hline \multicolumn{3}{|l|}{ Região de origem } \\
\hline Nordeste & 7 & 41,2 \\
\hline Sudeste & 10 & 58,8 \\
\hline \multicolumn{3}{|l|}{ Estado civil } \\
\hline Casada & 12 & 70,6 \\
\hline Separada & 4 & 23,5 \\
\hline Solteira & 1 & 5,9 \\
\hline \multicolumn{3}{|c|}{ Renda familiar (salários mínimos*) } \\
\hline$\leq 1$ & 1 & 5,9 \\
\hline $2-3$ & 14 & 82,3 \\
\hline$>3$ & 2 & 11,8 \\
\hline \multicolumn{3}{|c|}{ Número de dependentes da renda } \\
\hline 2 & 4 & 23,5 \\
\hline 3 & 6 & 35,3 \\
\hline 4 & 1 & 5,9 \\
\hline 5 & 6 & 35,3 \\
\hline \multicolumn{3}{|l|}{ Casa própria } \\
\hline Sim & 10 & 58,8 \\
\hline Não & 7 & 41,2 \\
\hline \multicolumn{3}{|l|}{ Saneamento básico } \\
\hline Sim & 16 & 94,1 \\
\hline Não & 1 & 5,9 \\
\hline \multicolumn{3}{|l|}{ Grau de escolaridade } \\
\hline Fundamental incompleto & 11 & 64,6 \\
\hline Fundamental completo & 2 & 11,8 \\
\hline Médio incompleto & 1 & 5,9 \\
\hline Médio completo & 2 & 11,8 \\
\hline Superior completo & 1 & 5,9 \\
\hline
\end{tabular}

*salário mínimo vigente: $\mathrm{R} \$ 350,00$. 
Tabela 2 - Características relacionadas à alimentação da criança

\begin{tabular}{lrr}
\hline & Sim & Não \\
\hline Ambiente familiar durante as refeições & & 12 \\
Presença exclusiva da mãe nas refeições & 5 & 9 \\
Momento da alimentação prazeroso & 9 & 3 \\
Dificuldades relacionadas à alimentação & 11 & 15 \\
Financeira & 14 & 16 \\
Transporte & 2 & 16 \\
Disponibilidade para compra & 15 \\
Atitudes preferenciais das mães frente à recusa de alimentos & 1 & 15 \\
Recompensa & 2 & 15 \\
Brincadeiras & 2 & 12 \\
Castigo & 2 & 6 \\
Persuasão & 5 & 14 \\
Conversa & 11 & 8 \\
Substituição da refeição por alimentos preferidos & & 0 \\
Alimentação e constipação & 3 & 9 \\
Relatos de que os filhos se alimentam bem & 9 & 5 \\
Alteração do apetite após estabelecimento do quadro de constipação intestinal & 17 & 8 \\
Importância da alimentação no tratamento & 12 & \\
Importância das fibras & & \\
Exclusão de alimentos "obstipantes" & & \\
\hline
\end{tabular}

só... Às vezes, naquele dia a criança não está muito bem; às vezes eu não estou muito para comer... Por que ele tem que comer todo dia tudo o que eu ponbo?"; "Ela não se recusa a comer, pois eu ponbo no prato dela só o que eu sei que ela vai comer"; "Eu a obrigava a comer na marra, ela tem que comer!".

Alteração do apetite após a estabelecimento do quadro de constipação intestinal com diminuição da ingestão alimentar foi relatada por $52,9 \%(9 / 17)$ das mães, como se pode observar nas falas a seguir: "Ah, um pouco porque parece que quando ele está nos dias em que não consegue ir ao banheiro ele não tem tanta vontade de se alimentar, né, parece que está cheio"; " $A b$, demais! Porque antes ele comia 'legalzinho', mas depois ele só quer duas colheres pequenas, ai você mal põe no prato. Feijão vocêpode dar que ele não pega. O apetite dele diminuiu bastante"; "Sim, porque como ela não fazia 'cocố ficava mais difícil dela comer"; "Antes eu forçava ela a comer, agora não forço mais devido ao problema que ela tem, aí eu falo para ela tentar comer mais tarde"; "Depois da barriguinha (referindo-se à constipação), foi ruim, porque antigamente ele comia até pedra".

Frente à recusa alimentar, a maioria das mães $82,3 \%$ (14/17) adota estratégias para convencer a criança a aceitar a refeição como podemos ler a seguir:

- recompensa e/ou barganha: "Eu falo que vou dar um doce, coisa que ela gosta"; "Eu prometo que vou deixar ele brincar, senão funcionar ela não come";
- brincadeiras: "Eu fico tentando fazer com que ele coma para ele não ficar com fome. Às vezes, eu ponho na boca, conto historinhas; faço um monte de tentativas que eu aprendi";

- castigo: "Digo que se ele não comer, ele apanha e, às vezes, resolve"; "Eu quero dar uns tapas nela, depois que eu dou ela come mais uma ou duas colheradas de comida";

- persuasão/conscientização: "Eu falo que ela precisa comer para não ficar fraca";

- conversa/diálogo: "Eu pergunto o motivo pelo qual ele não quer comer"; "Eu tento conversar com ele: filho, tenta comer...";

- substituição da refeição por alimentos preferidos: "Eu espero um pouco e ofereço uma mamadeira".

Quanto à atitude da mãe de oferecer alguns alimentos à criança quando ela está inquieta, chateada ou chorando, três $(17,6 \%)$ disseram oferecer frutas, oito $(47 \%)$ doces ou bolachas e seis $(35,2 \%)$ não oferecem nenhum alimento, como podemos ver nos relatos abaixo:

"A única coisa que eu faço é conversar com ele, perguntando o que está acontecendo"; "Faço ela deixar de ficar estressada, faço carinho"; "É só dar chocolate que ela deixa de ficar estressada"; "Sim, é a pera"; "É só dar bolacha para ele que ele fica quietinho".

Quanto ao último tema, conhecimentos maternos sobre alimentação e sua relação com a constipação intestinal, 
destacam-se as seguintes frases, quando as mães foram questionadas sobre quais alimentos são bons para a saúde de seus filhos: " $A h$, a mistura (referindo-se às carnes) porque tem muito mais vitamina que o arroz e o feijão"; "A rroz e feijão porque tem ferro"; "Bastante arroz e feijão, porque eu acho que é o prato que mata a fome"; "Verdura, porque eu acho que ela deixa o sangue mais forte, ah... eu acho, em minha opinião".

Destacam-se, também, alguns relatos das mães quanto ao uso de fibra para o funcionamento intestinal: "Com o uso da ameixa está funcionando melhor o intestino dela"; "A salada, porque eu acho que resolve mais o problema dela"; "Às vezes tem sim, eu gosto muito que ela coma verdura, legumes, essas coisas, porque solta o intestino dela; ele não funciona normalmente".

As mães relatam que há alguns alimentos que elas evitam oferecer aos filhos, pois consideram prejudiciais para a constipação crônica funcional ou para a saúde: "O pãazinho e a massa, porque prende muito; para ela prende demais e eu já acho ela gordinha, eu queria que ela fosse menos"; "Coisa muito gordurosa, por causa do problema dele, porque piora a constipação"; "Salgadinho, eu odeio aquilo! Porque aquilo lá é só isopor"; "Doce, porque eu sei que estraga os dentes, dá verme".

Quando as mães eram questionadas sobre o que gostariam que seus filhos comessem, mas eles não aceitam, notam-se respostas variadas: "Eu gostaria que ela comesse fruta, mamão, porque é mais saudável para ela"; "Fígado com batata ela não gosta, eu queria que ele comesse, pois uma colega minha disse que é muito bom, porque deixa mais forte, mas ele não come".

As entrevistadas foram questionadas sobre o fato de evitarem oferecer algum tipo de alimento para seus filhos por acharem que poderiam prender o intestino: " $A$ maçã , porque dizem que prende, aí eu dou só um pedacinho de nada"; "Tento não dar banana; maçã eu tento dar mais, o mamão, quando vou dar vitamina para ele; no meio do suco, eu coloco ameixa"; "Sim, o feijão e a maçã,, porque falam que prende o intestino".

Quando lhes foi perguntado se a alimentação tem alguma importância para o tratamento da CCF, todas as mães disseram que sim: "Ah, com certeza, porque não adianta só tomar remédio se a alimentação não é apropriada, porque ele vai ficar dependente do remédio e a alimentação piorando"; "Agora vai ter que mudar bastante coisa. Ab, como foi igual à minha menina, a médica mandou dar bastante verdura, beber bastante água, pois depois que ela comegon a comer couve-flor, brócolis, soltou mais o intestino"; "Com certeza, pelo que eu já vi aqui, antes eu não sabia não, mas agora que eu to acompanbando aqui, eu estou vendo que sim. Antes eu não obrigava ela a comer, se ela quisesse comer, tudo bem, se não, ela não comia, mas depois que eu comecei a passar aqui (ambulatório) eu vi que ela precisa comer nem que seja na marra; ela vai ter que aceitar, porque a criança também não come por culpa dos pais".

\section{Discussão}

O comportamento da criança durante as refeições, assim como suas preferências alimentares, geralmente reflete os hábitos alimentares de sua família, de acordo com as crenças, significados, condições socioeconômicas e valores ligados à alimentação.

Os resultados deste estudo revelam que a problemática socioeconômica, presente na maioria dos países em desenvolvimento, na qual o excedente de mão-de-obra e a escassez de oferta de emprego favorecem o desemprego e, por consequência, a falta de acesso às necessidades básicas do ser humano como saúde, educação e alimentação, são os principais fatores que influenciam as práticas alimentares das famílias.

Nesse contexto, o profissional nutricionista deve orientar os pais a optarem por alimentos mais saudáveis, exemplificar as variadas formas de preparo que preservem suas características nutricionais, bem como falar sobre o aproveitamento total dos alimentos.

Outra grande questão a ser enfrentada é a constante preocupação e ansiedade dos pais em oferecer os alimentos aos seus filhos, assim como a crença de que as crianças não conseguem regular a própria ingestão, o que faz com que os pais adotem estratégias que forcem a criança a comer além do necessário ${ }^{(14)}$. Essas atitudes, se persistentes ao longo do desenvolvimento alimentar da criança, podem causar uma predisposição a problemas como falta de saciedade, sobrepeso e obesidade infantil ${ }^{(15)}$.

Em estudo realizado por Birch $e t l^{(16)}$, observou-se que a ingestão energética foi relativamente constante. Se, em uma refeição, a criança ingerisse uma quantidade maior de alimentos, na refeição seguinte seu consumo seria menor e vice-versa, fato que sugere uma auto-regulação da ingestão, quando oferecida uma dieta balanceada.

Na literatura, a diminuição do apetite associada ao quadro de constipação intestinal está presente ${ }^{(17)}$, havendo relatos de menor consumo diário de energia, macronutrientes, ferro e fibras insolúveis em crianças com constipação, comparadas àquelas sem constipação ${ }^{(18)}$. Desse modo, durante a orientação nutricional, é importante explicar aos pais que essa baixa aceitação alimentar faz parte da sintomatologia da doença e, com o tratamento, a tendência é que o apetite melhore ${ }^{(19)}$.

Quanto à atitude das mães frente à recusa de alimentos, a barganha é uma forma de tentar, de qualquer forma, ali- 
viar a angústia do adulto diante de uma situação percebida como difícil, na tentativa de permutar uma condição árdua por uma compensatória. Com a mesma intenção, a adoção de brincadeiras desperta, na maioria dos casos, um interesse maior, da parte da criança, pelo momento da diversão do que pelo momento da alimentação. Por outro lado, o ideal é que as refeições sejam realizadas em local apropriado e tranquilo, de modo que a criança possa interagir positivamente com os alimentos que lhes são expostos ${ }^{(20)}$.

Muitas vezes, a intolerância à frustração e o sentimento de impotência do adulto perante uma situação de desprazer fazem com que eles atuem de forma concreta, com atitudes agressivas, no intuito de mostrar à criança o seu descontentamento e dor frente à sua recusa em se alimentar ${ }^{(21)}$.

A substituição da refeição por "alimentos preferidos" traz, em longo prazo, monotonia à dieta e desinteresse da criança, comprometendo seu hábito alimentar ${ }^{(20)}$, o que deve, portanto, ser evitado.

A crença de que alguns alimentos têm um efeito "obstipante”, isto é, pioram o quadro de constipação, é observada nos relatos das mães. Tais pensamentos, bem como o senso comum e as tradições familiares, ainda são aspectos relevantes na sociedade. O seu manejo é bastante complicado, uma vez que mexe com os vínculos e relações primárias do ser humano, transmitidos de geração em geração.

O tratamento da constipação crônica funcional inclui o acompanhamento médico e nutricional, havendo necessidade de que a criança incorpore hábitos alimentares que forneçam quantidades adequadas de fibras e de água. Nesse contexto, a família é a principal instituição que influencia os hábitos da criança, inclusive os alimentares, considerando-se que é a responsável pela compra, preparo e oferta dos alimentos.

Dessa maneira, cabe ao profissional nutricionista orientar, de maneira simples e objetiva, quanto à importância da ali- mentação no tratamento da constipação crônica funcional e na promoção da saúde, sempre levando em consideração as representações simbólicas, costumes, fatores culturais, psicológicos, sociais e econômicos agregados ao comportamento alimentar familiar.

Em um estudo brasileiro, feito com mães de crianças sob risco nutricional ${ }^{(13)}$, foram identificados fatores e atitudes, semelhantes aos encontrados nesta pesquisa, que influenciaram o comportamento alimentar das crianças, como: limitação financeira, crenças relativas a certos alimentos e suas consequências à saúde, assim como a forma de agir das mães diante da recusa dos filhos em aceitar a refeição.

A percepção das mães frente à alimentação de seus filhos, mesmo quando eles são saudáveis ${ }^{(12)}$, é semelhante aos resultados desse estudo quanto ao uso de estratégias para a aceitação das refeições pelas mães, mesmo quando consideram boa a alimentação de seus filhos ou creem que a ingestão de determinados alimentos é fundamental para a saúde do menor.

Dessa forma, pode-se concluir que a totalidade das mães de crianças com constipação intestinal crônica detem o conhecimento de que a alimentação é importante no tratamento dessa afecção, porém, apenas uma parte delas reconhece a importância das fibras alimentares. O fator financeiro é limitante em relação à possibilidade de oferta de alimentos mais adequados para as crianças com constipação intestinal. A refeição não é um momento prazeroso para inúmeras famílias e a conduta das mães é heterogênea em relação à recusa alimentar de seus filhos.

Novos estudos nessa linha de pesquisa são necessários para identificar até que ponto esses fatores e atividades, quanto às práticas alimentares, são diferentes nas crianças com constipação em relação às saudáveis, a fim de orientar os profissionais em relação a uma abordagem melhor a ser adotada em cada situação, que contribua para uma maior adesão às orientações nutricionais.

\section{Referências bibliográficas}

1. Partin JC, Hamill SK, Fischel JE, Partin JS. Painful defecation and fecal soiling in children. Pediatrics 1992;89:1007-9.

2. Loening-Baucke V. Constipation in early childhood: patient characteristics, treatment, and long term follow up. Gut 1993;34:1400-4.

3. Loening-Baucke V. Chronic constipation in children. Gastroenterology 1993;105:1557-64

4. Murphy MS. Constipation. In: Walker WA, Durie PR, Hamilton JR, WalkerSmith JA, Watkins JB, editors. Pediatric gastrointestinal disease. Philadelphia: Decker; 1991. p. 90-110.
5. Motta ME, Silva GA. Constipação intestinal crônica funcional na infância: diagnóstico e prevalência em uma comunidade de baixa renda. J Pediatr (Rio J) 1998;74:451-4.

6. Maffei HV, Moreira FL, Kissimoto M, Chaves SM, El Faro S, Aleixo AM. História clínica e alimentar de crianças atendidas em ambulatório de gastroenterologia pediátrica com constipação intestinal crônica funcional e suas possíveis complicações. J Pediatr (Rio J) 1994;70:280-6.

7. Morais MB, Maffei HV. Constipação intestinal. J Pediatr (Rio J) 2000;76(Suppl 1): 147-56. 
8. Rozin P. Sociocultural influences on human food selection. In: Capaldi ED, editor.Why we eat what we eat. The psychology of eating. Washington: APA; 1997. p. 233-63.

9. Gillespie $\mathrm{AH}, \mathrm{Achterberg} \mathrm{CL}$. Comparision of family interaction patterns related to food and nutrition. J Am Diet Assoc 1989;89:509-12.

10. Birch LL. Psychological influences on the childhood diet. J Nutr 1998;128 (Suppl 2):407S-10S.

11. Sherry B, McDivitt J, Birch LL, Cook FH, Sanders S, Prish JL et al. Attitudes, practices, and concerns about child feeding and child weight status among socieconomically diverse white, Hispanic, and African-American mothers. J Am Diet Assoc 2004;104:215-21.

12. Marins SS. Percepções maternas sobre a alimentação de pré-escolares que freqüentam instituição de educação infantil [tese de mestrado]. São Paulo: Unifesp; 2005.

13. Rotenberg S, Vargas S. Práticas alimentares e o cuidado da saúde: da alimentação da criança à alimentação da família. Rev Bras Saude Mater Infant 2004;4:85-94 .

14. Ramos M, Stein LM. Desenvolvimento do comportamento alimentar infantil. J Pediatr (Rio J) 2000;76(Suppl 3):S229-37.
15. Francis LA, Hofer SM, Birch LL. Predictors of maternal child-feeding style: maternal and child characteristics. Appetite 2001;37:231-43.

16. Birch LL, Johnson SL, Andresen G, Peters JC, Schulte MC. The variability of young children's energy intake. N Engl J Med 1991;324:232-5.

17. Motta ME, Silva GA. Sinais e sintomas associados à constipação crônica. J Pediatr (Rio J) 2000;76:222-6.

18. Morais MB, Vítolo MR, Aguirre AN, Medeiros EH, Antoneli EM, FagundesNeto $U$. Teor de fibra alimentar e de outros nutrientes na dieta de crianças com e sem constipação intestinal crônica funcional. Arq Gastroenterol 1996;33:93-101.

19. Speridião PG, Tahan S, Fagundes-Neto U, Morais MB. Dietary fiber, energy intake and nutritional status during the treatment of children with chronic constipation. Braz J Med Biol Res 2003;36:753-9.

20. Madeira IR, Aquino LA. Difficulties in the management of sleep and eating disorders. J Pediatr (Rio J) 2003;79(Suppl 1):S43-54.

21. Marcondes E. Anorexia. In: Brezolin AM, Colli AS, Marcondes E, Moysés MA, Dias MH, editores. Pediatria em consultório. São Paulo: Savier; 1985. p. 123-37. 